\title{
VESTÍGIOS AUTOBIOGRÁFICOS NA ESCRITA DE VIAGEM: O “DIÁRIO DE BORDO” (1934)
}

\section{JUSSARA SANTOS PIMENTA}

Universidade Federal de Rondônia

RESUMO Considerando como fonte as crônicas de viagem de Cecília Meireles, colecionadas no álbum intitulado "Diário de Bordo", este trabaIho tem como objetivo investigar os vestígios autobiográficos nelas contidos. Publicadas no final dos anos de 1934 pelo jornal carioca $A$ Nação, as crônicas registravam o cotidiano do navio e publicizavam as impressões da primeira viagem da poeta e educadora a Portugal, para conferências educacionais e literárias. Como escrita autobiográfica ou autorreferencial, tece os sentidos, as impressões e as expectativas da travessia, em um claro entrelaçamento da vida profissional com a esfera íntima da educadora, permitindo compreender parte do universo de quem escreve, de quem questiona o seu lugar e também o panorama cultural, político e educacional brasileiro do período.

Palavras-chave: Escrita autobiográfica. Cecília Meireles. Diário de viagem.

\section{ABSTRACT}

\section{AUTOBIOGRAPHICAL TRACES IN TRAVEL WRITING: THE "TRAVEL JOURNAL" (1934)}

Considering as a source Cecilia Meireles' travel chronicles collected in the album "Diário de Bordo" ("Travel Journal"), this work aims to research the autobiographical traces present in them. Published in the end of 1934 by A Nação newspaper, from the city of Rio de Janeiro, the chronicles recorded the routine of the ship and made public the poet and educator's impressions during her first trip to Portugal for educational and literary conferences. As autobiographical writing, the journal weaves the meaning, the impressions and the expectations on the journey in a clear interlacing of the educator's professional and private life, allowing the reader to understand part of the universe of the writer, who describes it, questions her own perspective and also the cultural, political and educational panorama in Brazil at that time.

Keywords: Autobiographical writing. Cecilia Meireles. Travel journal. 


\section{RESUMEN RASTROS AUTOBIOGRÁFICOS EN LA ESCRITURA DE VIAJE: EL "DIÁRIO DE BORDO" (1934)}

Teniendo en cuenta como fuente las crónicas de viaje de Cecília Meireles, coleccionadas en el álbum titulado "Diário de Bordo", este trabajo tiene como objetivo investigar los rastros autobiográficos contenidos en el mismo. Publicado a finales de 1934 por el diario A Nação de la ciudad de Río de Janeiro, las crónicas registraban la vida cotidiana del barco y hacían públicas las impresiones del primer viaje de la poeta y educadora a Portugal para conferencias educacionales y literarias. Cómo escritura autobiográfica o auto-referencial, teje los sentidos, impresiones y expectativas en una clara interrelación de la vida laboral con la esfera íntima de la educadora, permitiendo la comprensión de parte del universo de quién escribe, de quién cuestiona su lugar y también del horizonte cultural, político y educacional brasileño del periodo.

Palabras clave: Escritura autobiográfica. Cecília Meireles. Cuaderno de viaje.

Se ninguém sabe do que o passado é feito, uma inquieta incerteza transforma tudo em vestígio, indício possivel, suspeita de história com a qual contaminamos a inocência das coisas. Nossa percepção do passado é a apropriação veemente daquilo que sabemos não mais nos pertencer (NORA, 1993, p. 20)

\section{Viajar e narrar}

A escrita autobiográfica tem fascinado os pesquisadores, sobretudo os da História da Educação, pela riqueza de fontes e possibilidades que propicia. Cartas, bilhetes, diários íntimos e de viagem, apontamentos diversos, recortes de jornais, fotografias, cadernos de pensamento, cartões, telegramas e postais trocados com amigos, familiares, leitores e intelectuais são passiveis de delinear o perfil dos seus autores, suas preferências e seus gostos, reconstituir o universo cultural e o momento histórico, a inserção política e social dos correspondentes, além de serem importantes fontes sobre os bastidores da criação literá- ria desses intelectuais. Pela riqueza de possibilidades que carregam, tornam possivel averiguar, conhecer e se aproximar de distintos olhares e percepções, subjetividades e tendências, perspectivas e sensibilidades que entremostram, escondem, compartilham e elucidam, diferentes pontos de vista e de entendimento.

Os diários de viagem também podem ser considerados como fontes de escrita autorreferencial, ainda que não seja esse o seu objetivo primordial, assim sendo, interrogamos neste trabalho as crônicas de viagem de Cecília Meireles, colecionadas em um álbum intitula- 
do "Diário de Bordo", com o objetivo de investigar os vestígios autobiográficos nelas contidos. Escritas e publicadas no final do ano de 1934, pelo jornal carioca $A$ Nação, as crônicas registravam o cotidiano do navio e publicizavam as impressões da primeira viagem da poeta e educadora a Portugal, para conferências educacionais e literárias.

Como é sabido, Correia Dias e Cecília Meirelles, nossos companheiros de trabalho, estão de viagem para Portugal, confortavelmente instalados a bordo do "Cuyabá", excelente transatlântico da linha da Europa, do Lloyd Brasileiro. ${ }^{2}$

Os editores do jornal A Nação lembravam aos leitores a importância da presença do casal Cecília e Correia Dias. Ele, um dos pioneiros da nova arte pictórica no Brasil, com o seu apuro técnico, exercia influência na formação dos modernos artistas brasileiros, os quais - evoluindo cada um a seu modo - vieram a constituir o "ambiente" nacional das artes plásticas, até então confuso e nebuloso nas suas diretrizes, e imperfeito e estatístico nas suas realizações. Correia Dias era um mestre exímio em todas as modalidades da pintura e da decoração, um escultor de largo fôlego, audacioso $e$ "emancipado" na concepção, e seria o responsável pelas ilustrações das crônicas escritas por Cecília Meireles. Mas os maiores elogios foram tecidos a Cecília Meireles: ela era a Vestal do Fogo Eterno da Poesia e possuía uma individualidade singular e resplandecia no cenário da [...] literatura moderna, como uma estrela de Libertação. Além das qualidades literárias, ressaltavam os relevantes serviços prestados à educação brasileira. Cecília Meireles possuía uma visão larga dos modernos problemas edu-

1 Cecília Meireles produziu um diário íntimo de viagem, que se encontra aos cuidados dos herdeiros e não está disponível para consulta. A publicação das crônicas não tem uma regularidade cronológica, a depender da escala do navio. Em determinadas datas, foram publicadas até três crônicas escritas em três datas diferentes.

2 Nota do editor do jornal A Nação. cacionais, cujo desdobramento e uma das suas iniciativas fecundas era a criação do Centro de Cultura Infantil no Pavilhão Mourisco (A Nação, 1934. p. 2). ${ }^{3}$

Nos anos de 1930, Cecília Meireles estreou no jornalismo, a princípio, dirigindo, com a colaboração de Correia Dias, a "Página de Educação" e a "Página das Crianças", no Diário de Notícias. Em janeiro de 1933, ao se desligarem do Diário de Notícias, principiaram a colaboração no jornal A Nação, dirigido por Antunes Neiva e secretariado por Azevedo Amaral, Cecília Meireles manteve a coluna "Comentário", na seção de educação, enquanto Correia Dias ilustrava o "Suplemento Literário", aos domingos. Em março de 1933, os "Comentários" e a seção de educação foram, ambos, reduzindo-se, gradativamente. Cecília Meireles passou a redatora, logo em seguida, até abandonar, definitivamente, o "Suplemento Semanal", em novembro de 1933. De janeiro a meados de junho de 1934, colaborou no suplemento literário e, na segunda metade do mesmo mês, inaugurou a coluna "Crônicas Semanais", desta vez escrevendo prosa. A sua participação no jornal $A$ Nação foi suspensa, em 31 de março de 1935, com a mudança na direção do jornal.

Depois de deixar o jornal A Nação, Cecília Meireles passou a escrever para o jornal Gazeta de Notícias, no qual publicou, em 20 de novembro de 1935, o artigo "Uma poetisa brasileira em terras de Portugal". Também em março desse ano saiu o primeiro número da segunda fase da revista Festa, quando ocorreu um hiato nesta colaboração devido à viagem de Cecília e Correia Dias a Portugal. Ela só reapareceu no número sete (7) da revista, em março de 1935. Entre 1944 e 1963, Cecília Meireles publicou as suas crônicas de viagem, em jornais como o Diário de Notícias, A Manhã, Folha Carioca (As crônicas "Rumo: Sul”, de I a

3 Nota do editor do jornal A Nação. Para mais informações sobre a criação do Centro de Cultura Infantil do Pavilhão Mourisco, consultar Pimenta (2011). 
XXV, foram publicadas pelo jornal Folha Carioca, entre junho e outubro de 1944) do Rio de Janeiro e Jornal de Notícias, Correio Paulistano e Folha de S. Paulo, de São Paulo. A temática que surge de maneira ainda embrionária nas "Crônicas de Educação" do Diário de Notícias tornou-se mais consistente e vigorosa em seus livros e, em prosa e verso (DAMASCENO, [s.d.]).

As crônicas da primeira viagem de Cecília Meireles e Correia Dias inseriam-se nessa colaboração que o casal fazia ao jornal $A$ Nação e, ainda, por sua evidente e reconhecida competência e prestígio junto aos círculos literários e educacionais: pela colaboração em revistas, como Árvore Nova, Terra de Sol e Festa (1a e 2a fases), bem como nos periódicos já citados. Reconhecidamente, Cecília Meireles realizava um trabalho diferenciado e rigoroso em prol da educação, cabendo destacar a "Página de Educação", a participação como signatária do Manifesto dos Pioneiros da Educação Nova, a adoção do seu livro Criança, meu amor (1923), em 1924, pela Diretoria de Instrução Pública e pelo Conselho Superior de Ensino dos estados de Minas Gerais e Pernambuco, e a criação da primeira biblioteca infantil brasileira.

As crônicas do "Diário de Bordo" eram diárias, foram escritas entre 21 de setembro a 12 de outubro, publicadas aos domingos, no período entre 21 de outubro a 30 de dezembro de 1934, e decorriam dos acontecimentos cotidianos do navio "Cuyabá". ${ }^{4}$ Percebe-se que mais

4 As crônicas foram colecionadas por Cecília Meireles em um álbum intitulado "Diário de Bordo" e cedidos, gentilmente, pela família da poeta. Nele também puderam ser encontrados dezenas de recortes de jornais portugueses, como Diário de Lisboa, Diário de Notícias, Diário da Manhã, Diário de Coimbra, e de revistas como Sempre Fixe, Portugal Feminino; de jornais e revistas brasileiros como A Tarde, Jornal do Commércio, A Vanguarda, Diário de Notícias, Diário Português e Festa, respectivamente, revelando a cobertura que a imprensa portuguesa e brasileira concedeu às atividades desenvolvidas por Cecília Meireles durante a sua permanência em Portugal. Nele também pode-se encontrar recortes, em menor número, sobre a viagem de volta, publicados em jornais brasileiros e que informam aos leitores o retorno e os sucessos da viagem e das conferências em terras portuguesas. que ser fiel aos acontecimentos do navio, também é possivel entrever algumas pistas que levam a narrativa a se conectar com a proposta da viagem. É a viagem de uma intelectual comprometida com questões literárias e educacionais e, sendo assim, o relato resvala do cotidiano para tocar questões inerentes às suas próprias convicções e inquietações a respeito do momento político e educacional que o país atravessa e Cecília Meireles se utiliza desse canal de comunicação para dialogar com os seus leitores sobre algumas dessas questões, ainda que não seja esse o mote das vinte e duas (22) crônicas. É possivel distinguir, na narrativa, que o relato das atividades cotidianas do navio é mais nítido, na primeira fase da viagem, e, o outro, mais introspectivo, está circunscrito às conexões que a narradora estabelece consigo mesma, com o silêncio e a solidão do passar dos dias e das noites a bordo.

O "Diário de Bordo" é um diário de viagem e ainda que não possa ser considerado um diário íntimo, já que não tem por objetivo primordial "contribuir para a construção da identidade pessoal de sua autora" (FERREIRA, 1998, p. 7), inscreve-se numa perspectiva autobiográfica, por se tratar de um texto em que "el sujeto habla o se refiere a sí mismo"'; (VIÑAO, 2000b, p. 11). Dessa forma, por ter a si mesmo como referência, o que se escreve passa por diferentes crivos, sanções pessoais e sociais, apresenta impedimentos: se escreve o que se pode escrever, o que é permitido, "seja em função da memória, de sua posição social ou mesmo de suas possibilidades de conhecimento [...]" (ALBERTI apud PIRES, 2010, p. 6).

Para Lacerda (2000, p. 84), uma das características da escrita autobiográfica encerra-se naquilo que cada narrador deseja registrar a partir do seu discurso: a veracidade de suas

As crônicas do "Diário de Bordo" foram recentemente publicadas e podem ser consultadas em sua integralidade em: Meireles, 2015.

5 [...] o sujeito fala ou refere-se a si próprio (VIÑAO, 2000, p. 11). 
lembranças aparece como produto "de um testemunho ocular da história de seu tempo, como se cada escritor pudesse elaborar seu discurso de forma impermeável às contradições, às interpretações pessoais e às subjetividades." Seu testemunho é permeado por essas contradições e embates pois:

O indivíduo não existe só. [...] Na vida de um indivíduo, convergem fatos e forças sociais, assim como o indivíduo, suas ideias, representações e imaginário convergem para o contexto social ao qual ele pertence. (DEL PRIORE, 2009, p. 10)

Diferentes viajantes imprimiram nas páginas de cadernetas as lembranças de suas jornadas a outras cidades e países. Esses viajantes, por estarem imersos em suas memórias e tendo como parâmetros as regras e os valores de seu contexto e de seu tempo histórico, deixaram marcas que se manifestam, ora aqui ora ali, em suas narrativas. Uma preocupação recorrente nos relatos estudados por Pimentel (1998) é que aqueles que viajam não querem ser considerados como turistas, pois se atribuem um status diferente. Segundo a autora, "uma coisa é ser turista, outra é ser viajante" (1998, p. 57). Os turistas são vistos como viajantes desinformados, sem tempo, e, consequentemente, sem atenção ao que veem. São diferenciados em sua formação, seus objetivos e o seu olhar, entre outros atributos que eles possuem e de que os turistas jamais serão detentores. Em uma crônica intitulada "Roma, turistas e viajantes", de 1953, Cecília Meireles parece querer assinalar, definitivamente, as diferenças existentes entre turistas e viajantes. O viajante é feliz e o "seu destino é caminhar pela superficie das coisas [...] comprando o que the agrada, expedindo muitos postais, tudo com uma agradável fluidez, sem apego nem compromisso" [...]. Já o viajante "possui movimentos mais vagarosos, todo enredado em afetos, querendo morar em cada coisa, descer à origem de tudo." o viajante permi- te-se "amar loucamente cada aspecto do caminho, desde as pedras mais toscas às mais sublimadas almas do passado, do presente e até do futuro" que talvez nem vá presenciar (MEIRELES, 1999, p. 101-104).

O turista feliz já está em sua casa, com fotografias por todos os lados, listas de preços, pechinchas dos quatro cantos da terra. E o viajante apenas inclina a cabeça nas mãos, na sua janela, para entender dentro de si o que é sonho e o que é verdade. (MEIRELES, 1999, p. 101-104)

Essa idealização do viajante, ou mesmo o status de herói que o viajante possuía até o século XIX foi, de acordo com Souza (1995), afetado pela modernização dos meios de transporte, pela diversificação dos roteiros e pela melhoria das condições de vida. Esses foram alguns dos fatores que popularizaram o hábito de viajar e modificaram o viajante, os seus objetivos e interesses. As modificações impulsionadas pelo progresso material introduziram "a velocidade no universo da viagem", fator que reduziu as distâncias e alterou a percepção do tempo (SOUZA, 1995, p. 63). Essas, além de modificarem o ritmo, vulgarizaram as viagens. Mais rápidas e com menor custo, as viagens tornaram-se mais acessiveis a outros extratos sociais e deixaram de ser um privilégio das classes mais abastadas. A arte de viajar abrangia "práticas que o desenvolvimento do turismo de massas dissolveu e o turista tornou-se, portanto, um viajante sem alma, desprovido de valores essenciais e da capacidade perceptiva do viajante clássico" (SOUZA, 1995, p. 64). Ao avançar e sofisticar-se a indústria do "turismo banalizou a figura do turista a ponto de torná-lo um estereótipo risível", como assinalado por Pimentel (1998, p. 57). Dessa forma, nada mais natural que o viajante da elite não quisesse se parecer com esse consumidor compulsivo de trens, hotéis e monumentos. O viajante, porém, concebe a viagem sob um ponto de vista diferenciado, pois ela é uma oportu- 
nidade de crescimento intelectual; além disso, ela confere distinção em relação ao demais:

o preconceito contra o turista atribuía uma qualidade diferente ao viajante civilizador, que aparece como sujeito de uma experiência, ao contrário do turista, mera peça de um esquema pré-resolvido. 0 viajante viajava de maneira especial. Sua missão, qualquer que fosse o motivo de sua viagem, era observar, refletir, comparar, e, em aqui chegando, divulgar, ensinar, civilizar. O turista, sendo um viajante sem esse compromisso, apenas ia de um lugar ao outro tentando tirar proveito próprio de suas andanças. Havia ainda, no início do século, a figura de um outro viajante, o globe-trotter, que nem era o turista e nem o viajante civilizador. Comparado ao turista, em alguns casos, caracterizava-se pelo 'prazer physico de se movimentar', mas, diferente do turista, não tinha a exigência do conforto e da comodidade como condições da viagem. (PIMENTEL, 1998, p. 66)

Em se tratando dos viajantes intelectuais brasileiros, a viagem era um privilégio dos bem-nascidos. Viajar era uma forma de conferir pessoalmente a superioridade da cultura europeia. Tomando como objeto as narrativas de viagem de intelectuais brasileiros, Santos (2002) constata que esta é uma questão muito mais complexa. A autora identifica, a partir dessa produção, dois eixos centrais, distintos entre si, quanto às relações viagem/escrita, e que permitem a elaboração de duas linhagens de viajantes, que para ela têm a vantagem de possibilitar a aproximação por semelhança, de escritores de diferentes gerações que compartilham formas de escrever e viajar também distintas. Ela divide os viajantes-narradores em duas linhagens: Nabuco e Modernistas. Os primeiros, à semelhança de seu inspirador, Joaquim Nabuco, entendem a travessia do Atlântico como uma oportunidade de ratificar a superioridade cultural europeia, e mais particularmente, da França. Para os Modernistas, o objetivo da viagem não significa mais a confirmação dessa supremacia, mas passa a servir à construção de uma tradição cultural brasileira. Como Pimentel (1998), a autora também constata a necessidade que "os autores de livros de viagem têm em explicitar aos seus leitores que estão na companhia de um viajante legítimo" (SANTOS, 2002, p. 12).

Para os filhos diletos de uma elite econômica e cultural, a viagem era a confirmação da sua educação europeia, uma das etapas da sua formação intelectual e pessoal e se limitaria à mera excursão, se não fosse registrada (SANTOS, 2002, p. 76). A perspectiva conservadora ou transformadora que a viagem conferia ao viajante também era responsável pelas diferenças que marcavam o tom das suas narrativas. ${ }^{6}$ Duas possibilidades apresentavam-se: ou o intelectual ia à Europa conferir o que já sabia pela educação e pela literatura e se ligava “à terra natal pelo afeto e à Europa pela inteligência" (SANTOS, 2002, p. 88), como afirmava Joaquim Nabuco7 (e era o mesmo que se encantava pela superioridade cultural do Velho Mundo), ou era o viajante modernista. Esse segundo tipo de viajante seria aquele que "apesar de conhecer a trilha que the é reservada desde o princípio de sua formação, [...] desviase dela em direção a elementos novos que lhe possibilitem construir um outro roteiro" que lhe permita um outro tipo de escrita em que registrava não o que já está solidificado, mas problematizava os seus caminhos. Esse roteiro de viagem, por fim, conduziria "os passos do

6 Segundo a autora, a viagem tem um caráter conservador, quando contribui apenas para confirmar e reiterar os privilégios e o pertencimento do viajante a uma elite intelectual, e ratificar a supremacia da cultura europeia. Não produz mudanças efetivas nas concepções do viajante, que só verifica o que já sabe. $A$ viagem supostamente cumulativa e, portanto, de formação revela-se falsa quando se descobre, encoberta sob a superficie de aparente mudança, a permanência. É transformadora na medida em que contribuiria para levar o viajante a rejeição a uma atitude deslumbrada e a rever sua atitude frente à realidade de seu pais de origem. (SANTOS, 2002, p. 88)

7 Joaquim Aurélio Barreto Nabuco de Araújo (1849-1910) político, diplomata, historiador, jurista e jornalista brasileiro. Foi um dos fundadores da Academia Brasileira de Letras. 
viajante de volta ao Brasil, pois a descoberta iniciada em plena Europa" deveria prosseguir em solo brasileiro (SANTOS, 2002, p. 112-113).

Uma distinção em relação ao viajante é feita por Leite (1997), quando aponta as diferenças intrínsecas deste e o habitante, ao afirmar que como não faz parte do grupo cultural visitado, o viajante tem condições de perceber aspectos, incoerências e contradições da vida quotidiana que o habitante, ao dá-la como natural e permanente, encontra-se incapaz de perceber. Dessa forma, o habitante, por estar entranhado em sua realidade sociocultural, “reflete apenas sobre seus aspectos mais próximos, sem tomar conhecimento de muitos outros do ambiente em que se encontra, e aceita, quase que tacitamente as instituições, as interrelações sociais, os sinais, as indicações e orientações, que compõem o padrão cultural do grupo social a que pertence", sem fazer uma reflexão mais ampla (LEITE, 1997, p. 10). A autora refere-se, ainda, às diferenças existentes entre viajantes e imigrantes, segundo a qual, não "é apenas a viagem de vinda sem retorno que diferencia o viajante do imigrante." Se o primeiro pretende conservar os padrões culturais de sua comunidade original, o segundo já apresenta uma predisposição "a incorporar os esquemas mentais do povo visitado, no pior dos casos como um meio de aprimoramento de sua percepção-do-outro, para ser aceito e manter relações amistosas ainda que cheias de mal-entendidos" (LEITE, 1997, p. 10). A mobilidade social e econômica de que ambos desfrutam lhes dá autonomia a ponto de poderem “observar, descrever e classificar em termos ordenados de acordo com ideais científicos de coerência, consistência e consequência analítica questões que, para o habitante daquele universo social, constituem um campo de atos possiveis, só secundariamente constituintes do objeto de reflexão sistemática" (LEITE, 1997, p. 162). Por ser estranho ao grupo, o viajante pode e observa comportamentos, hábitos e ideias que passam despercebidos aos habitantes do país.

A narrativa presente no "Diário de Bordo" difere bastante dos relatos do primeiro tipo de viajantes. Não pode ser considerada conservadora, de acordo com a perspectiva desenvolvida por Santos (2002), segundo a qual a viagem é conservadora, se e somente se contribui para confirmar os códigos que o viajante já possui. Encontra mais similitudes com a perspectiva transformadora, pois Cecília Meireles coloca em xeque as suas concepções a respeito de si e do mundo. Há que se pensar também que são diversos os motivos que a levam a Portugal, distintos dos comumente percorridos pelos educadores brasileiros. Ao se dirigir ao país europeu, a educadora não vai somente em busca dos novos cânones educacionais que estão sendo divulgados, mas levar a experiência brasileira para ser conhecida, contribuindo no debate internacional que ora se realizava (PIMENTA, 2007, p. 173). Outra particularidade do relato de Cecília Meireles é surgir das reminiscências de um poeta. Como afirma Bakidian (1988) todos os poetas são viajantes, já que se permitem às viagens literárias, metafóricas e/ ou fictícias e procuram transformá-las em experiências concretas que em ocasião propícia servirão de substrato para novas viagens imaginárias (BAKIDIAN apud SANTOS, 2002, p. 29).

Em diferentes oportunidades, Cecília Meireles procurou fazer uma diferenciação entre os termos turista e viajante. Essa não é uma operação gratuita, uma vez que nessa caracterização que faz dos dois termos estão impressas as suas representações, isto é, os seus valores, as suas crenças, o seu lugar social, a sua educação etc. Nessa distinção, mais ligada ao amadurecimento intelectual e humano, o turista não é, segundo ela, um poeta, nem um historiador, nem um sábio, pois é cheio de exigências, ávido por ver o panorama e extrema- 
mente preocupado com pequenos detalhes, ao invés de se extasiar diante de uma igreja ou de um museu. 0 viajante, por outro lado, não se queixa dos trens quebrados, dos automóveis sem molas, das estradas, da poeira ou dos mosquitos, pois estão possuídos "de sonho e fanatismo da mais pura qualidade" (MEIRELES, 1999, p. 71).

No "Diário de Bordo", a palavra turista sequer é mencionada e Cecília Meireles emprega o termo viajante em apenas meia dúzia de oportunidades. 0 termo passageiro é utilizado vinte e uma (21) vezes. O que fica visivel, em suas crônicas, são as suas representações sobre cada uma dessas categorias apontadas e o sentido que a viagem tem para cada qual e como cada um deles viaja. Dessa forma, Cecília Meireles define a maior parte dos seus companheiros de viagem como passageiros. Passageiros não são viajantes. Passageiros deslocam-se de um ponto ao outro, utilizando um meio de transporte, portando bagagens e a necessidade de chegar ao seu destino. Como a própria palavra sugere, passageiros são aqueles que se encontram de passagem. Os passageiros, de acordo com Cecília Meireles, concebem a viagem sob um ponto de vista demasiado prático, estabelecem uma relação utilitarista e desde o momento do embarque não se admiram, não se comovem com a paisagem, nem com as amizades ou com o ambiente de bordo, pensam "exclusivamente nisto: chegar" (MEIRELES, 1934, p. 2). Para ela, as viagens têm um sentido muito mais profundo e são consideradas uma aventura do espírito, uma forma de aprendizado e de crescimento interior. Pelas considerações que faz, compreendemos a própria Cecília Meireles como o viajante que ela descreve. Ela é o viajante, pois encerra em si mesma a capacidade de se admirar, a disponibilidade para aprender, é quem tem tempo e curiosidade para ver, sentir, se emocionar, e sensibilidade para amar as surpresas.

\section{Refúgios do eu, refúgios de todos}

Diferente dos romances cuja característica ficcional fica evidenciada e das autobiografias em que o autor acessa os acontecimentos passados, de acordo com Ferreira (1998, p. 378), "o diário representa um tempo presente contínuo acompanhando uma história de vida imprevisivel e imponderável." A autora destaca o caráter privado e intimista dessa escrita como uma característica que vigorou até o início do século XX. Nos diários, os autores procuravam enfatizar "experiencias, aliviar tensões, permitir o autoexame, relatar grandes acontecimentos, exaltar qualidades e valores, estimular o aprimoramento pessoal e demonstrar capacidade de autocontrole" (FERREIRA, 1998, p. 379). Já nos dias de hoje, os diários são construídos tendo em vista publicizar experiências e impressões de seus autores. O "Diário de Bordo" não é um diário íntimo. O "Diário de Bordo" não é um diário de viagem que, por algum motivo, foi tornado público. Ele é um diário de viagem organizado com uma intencionalidade, qual seja: a de tornar público o relato nele contido em um jornal de ampla cobertura e que atingia leitores diferentes, distintos.

Só em sentido amplo, os diários de viagem podem ser considerados autobiográficos, assevera Viñao (2000a), uma vez que em muitos deles o autor fala muito pouco ou quase nada de si mesmo e, quando o faz, limita-se a narrar o que viu ou o que aconteceu:

Si se considera autobiografía, no siempre adecuadamente, la narración de algo vivido o acaecido al autor del texto en cuestión, ¿cómo no considerar los libros de viajes una modalidad más de dicho género, aunque las referencias a sí mismo sean mínimas? ¿No se consideran autobiografias aquellas obras en las que, bajo este título u otros, el autor da cuenta de sus recuerdos aunque éstos se refieran total o parcialmente a personas sin relación en el mismo 
o a acontecimientos en los que no tuvo participación? ${ }^{8}$ (VIÑAO, 2000a, p. 13)

Como também coleciona impressões íntimas de sua autora, o diário de viagem de Cecília Meireles configura-se dentro do que se convencionou caracterizar como autobiográfico, pois "transborda da escrita [...] suas escolhas e também suas tensões e emoções" (MIGNOT; SILVA, 2011, p. 447). Quando essas emoções são explicitadas, a narrativa de viagem converte-se naquilo que Viñao (2000b, p. 15) salienta: "cuando lo público se privatiza, lo privado se hace público y deviene objeto de interés geral. Ocupa el espacio de lo público, transformando los refúgios del yo em refúgios, al menos potencialmente, de todos" ${ }^{\prime \prime}$. Sendo assim, quando as concepções da esfera íntima dos autores mesclam-se às da esfera privada tornando-se públicas, são apropriadas pelos leitores que contrastam as suas vivências, angústias, alegrias e tristezas, os pensamentos e as suas lembranças mais intimas. Dessa forma, podemos pensar que, ao ler as crônicas de viagem de Cecília Meireles, leitores de qualquer tempo e espaço sejam capazes de refazer cada percurso, de se enlear em cada sensação e de tecer diferentes refúgios para si mesmos.

Um tipo singular de narrativa de viagem é de autoria da escritora potiguar Nísia Floresta. Tomando as suas impressões sobre os lugares visitados, observamos que a mesma subverte o que se espera de um diário de viagem, ou

8 "Se se considera a autobiografia, nem sempre corretamente, como a narrativa de algo vivido ou acontecido ao autor do texto em questão, como não considerar os livros de viagem uma outra forma de realização deste género, ainda que as referências de si mesmo sejam mínimas? Não se considera autobiografias aquelas obras em que, sob este título ou outro, o autor conta as suas memórias, ainda que elas se relacionem total ou parcialmente a pessoas sem relação com ele mesmo ou a eventos em que eles não tiveram participação?"

9 "[...] quando o público se privatiza, o privado se torna público e torna-se objeto de interesse geral. Ocupa o espaço do público, transformando os refúgios do eu em refúgios do eu, ao menos potencialmente, de todos". seja, que nele se trate exclusiva e unicamente dos aspectos vistos e vividos durante um trajeto relatado de forma cronológica. Nísia não privilegia os aspectos externos da viagem, mas a sua "própria subjetividade, ou seja, as emoções que os objetos e os lugares lhe despertam." São as emoções que comandam a direção da narrativa. Por meio da memória, "ela busca reminiscências da infância, ou vai ao encontro de familiares distantes [...]. A narradora se coloca no centro da escritura, se auto contempla romanticamente, e tudo o mais parece girar à sua volta" (DUARTE, 2009, p. 73). A escrita de viagem de Nísia Floresta também não está exclusivamente contida em diários de viagem e é encontrada também sob a forma de "memórias, confissões ou crônicas" (2009, p. 80). Nísia Floresta introduz, sistemática e intencionalmente, “informações de cunho biográfico em sua obra, é daquele tipo de ficcionista que faz da forma autobiográfica de expressão um traço inerente de seu processo criativo" (DUARTE, 2009, p. 74). O inusitado dos relatos de Nísia Floresta é que ela incorpora o mesmo tipo de independência com que pautou a sua vida, ou seja, ela ignora os limites do público e privado, tornando públicos episódios de sua vida pessoal. "Em alguns textos fala explicitamente de si mesma, de sua infância, do companheiro falecido precocemente, das saudades da pátria e dos familiares" (DUARTE, 2009, p. 75). De acordo com Duarte (2009, p. 77), Nísia Floresta faz de si o centro da narrativa:

O que realmente importa - para ela e, por consequência para os leitores -, vão ser as emoções e as impressões que sente diante do que vê ou do que ouve. Nísia não só seleciona o que vai contar, como explicita a maneira de fazê-lo: sua emoção diante dos acontecimentos funcionará quase como um filtro e só através dela conhecemos cada aspecto de sua viagem.

Os relatos de Nísia Floresta são tão diversos do estabelecido a ponto de, em um mes- 
mo texto, realizar uma fusão do diário íntimo com o diário público, ou melhor, ela inicia o seu texto como um diário de viagem e termina como uma crônica histórica, realizando, no texto, "uma fusão entre as duas formas de diário, o de viagem e o diário íntimo, além de guardar uma semelhança com o gênero epistolar, quando se dirige a outra pessoa" (DUARTE, 2009, p. 80), realizando uma "simbiose entre o autobiográfico e a narrativa de viagem, o que contribui para tornar o seu relato um texto ímpar, diverso dos conhecidos até então" (DUARTE, 2009, p. 81). Então, o que se pode observar em relação aos diários de viagem e às escolhas do narrador é que estas são escolhas próprias. Cada qual toma para si a forma com que vai imortalizar o seu relato.

Um outro tipo de escrita de viagem foi pesquisado por Mignot e Silva (2011), que tomam como fontes primárias os relatórios de três educadores brasileiros que viajaram para estudar o sistema educacional de distintos países. Em meio à impessoalidade estabelecida como pré-requisito para a elaboração desses documentos, as autoras destacam as marcas de si encontradas, definindo os modos de ver o mundo dos professores viajantes, e que trazem em sua narrativa "[...] mais do que impressões, conclusões e proposições sobre a organização escolar, a organização do magistério, o material didático, a arquitetura das escolas e os aspectos relativos à remuneração dos professores [...]: entremostram traços de intimidade" (MIGNOT; SILVA, 2011, p. 435).

No “Diário de Bordo", por sua vez, não há uma cobrança para que a impessoalidade seja a tônica, como requerido nos relatórios construídos pelos professores comissionados supracitados. Cecília Meireles pode dar vazão aos transbordamentos, às efusões da sensibilidade, da crítica, da confissão, do riso e da galhofa e até mesmo da puerilidade, já que a narrativa é dirigida e dedicada ao público lei- tor de um suplemento de um jornal popular. Diferenciado e livre, portanto, de exigências formais. A narrativa precisa e deve ser saborosa e lúdica, a ponto de cativar leitores de todas as idades, extratos sociais e preferências estéticas.

Em estudo que investiga o diário de viagem de D. Pedro II a Minas Gerais, em 1881, como um exercício de escrita autorreferencial, Pires (2010) identifica duas vertentes na narrativa: uma da viagem e outra da memória, que se confunde com o tempo da escrita. Os diários de D. Pedro II revelam aquilo que é comum aos diaristas e viajantes: em primeiro lugar, o viajante escreve para si mesmo, pois escreve para “criar uma imagem de si para si" (PIRES, 2010, p. 7). o imperador, além de escrever para si e sobre si, vai revelando as ações que desenvolve durante as suas viagens:

D. Pedro II quase nunca faz análises profundas, é uma escrita quase taquigráfica, cheia de repetições: em cada cidade que chega se repete os procedimentos do dia-a-dia e, também, os da escrita. É um tipo de diário crônica: com registros e apontamentos da vida pública, daquilo que é feito aos olhos de todos, na função de Imperador. Não há quase nada sobre a vida priva$\mathrm{da}$, sua mulher que o acompanhava é citada somente três vezes - e sem se aprofundar, parece que ela é mais um da comitiva -, os problemas domésticos com a viagem não são de interesse para a escrita, não é um diário íntimo, apenas [...]. (PIRES, 2010, p. 8)

As crônicas do "Diário de Bordo" carregam uma outra lógica. Em cada uma delas há um relato diferente e esta é uma característica da escrita que quer cativar um público leitor. Não pode ser enfadonha, repetitiva, desprovida de sabor, burocrática. Pode ser profunda, mas leve, como é a escrita ceciliana, sem pedantismos desnecessários. Em suas crônicas, Cecília Meireles guarda os testemunhos da viagem que são, de certa forma, uma estratégia para arquivar lembranças, paisagens vistas e 
vividas e se constitui num projeto autobiográfico. As crônicas são escritas como uma maneira de "colecionar os dias" (MUZART, 2000, p. 183), arquivando nesse suporte da memória os fatos vivenciados e as impressões delas advindas.

À medida em que desaparece a memória tradicional, nós nos sentimos obrigados a acumular religiosamente vestígios, testemunhos, documentos, imagens, discursos, sinais visiveis do que foi, como se esse dossiê cada vez mais prolífero devesse se tornar prova em não se sabe que tribunal da história. (NORA, 1993, p. 15)

Depois de arquivadas em crônicas que serão, por sua vez, publicadas pelo jornal “ $\mathrm{A} \mathrm{Na-}$ ção", a própria Cecília estabelece um novo arquivamento e dessa vez não é mais a memória que se arquiva, mas o produto dela, materializado sob a forma de recortes que serão mais uma vez organizados, classificados e colados em seu álbum particular, também intitulado "Diário de Bordo". Essas memórias arquivadas e organizadas "em função de um futuro leitor" (MIGNOT, 2000, p. 126) vão permitir proteger do tempo e conservar as realizações daqueles que, mesmo estando muitas vezes "nos bastidores da política educacional [...] não estavam distantes das questões de seu tempo". Selecionando primeiro vivências e lembranças e depois papéis, indica suas afinidades eletivas, prioriza e resguarda do tempo e do esquecimento resquícios do "tempo das realizações corajosas", quando (MIGNOT, 2000, p. 137-138) um grupo de educadores, mulheres e homens, se dispuseram a mudar a face educacional do país. Num momento em que as mulheres "transitavam do universo privado para a cena pública", como afirma Mignot (2000, p. 124), as crônicas do "Diário de Bordo" revelam-se estratégias de visibilidade, conferem legitimidade à produção, evidenciam e inscrevem a presença de Cecília Meireles nos embates e questões dos debates de sua época.

\section{Um bric-à-brac ambulante}

Em determinada parte da narrativa, Cecília Meireles compartilha algumas das atividades realizadas durante o desembarque nas cidades costeiras: Wolkowisky, um dos companheiros mais assíduos do casal na viagem, compra livros franceses; Correia Dias compra material de desenho e pintura para trabalhar a bordo; ela devasta as papelarias, procurando coleções de postais. Também compram joias, artigos de papelaria, um relógio, livros velhos, uma coleção de literatura de cordel. Se continuarmos assim, chegaremos à Europa sem vintém - mas em condições de montar um estabelecimento comercial (MEIRELES, 1934). São comprados materiais diversos que são colhidos e escolhidos aleatoriamente.

Porque é afetiva e mágica, a memória não se acomoda a detalhes que a confortam; ela se alimenta de lembranças vagas, telescópicas, globais ou flutuantes, particulares ou simbólicas, sensivel a todas as transferências, cenas, censura ou projeções. (NORA, 1993, p. 9)

A memória organiza-se tal qual um bricà-brac: ao sabor do imprevisivel. Embora seletiva, coleciona passagens, espaços, acontecimentos e imagens movediças, mutáveis, impalpáveis, concretas ou fugidias, de forma aleatória, como também são as imagens que o narrador tem dos acontecimentos e de si, a depender dos encontros, dos relacionamentos, dos espaços visitados e percorridos, ou seja, o que fica registrado nos diários também apresenta essa mesma falta de coesão e imprecisão. Segundo Pires (2010), a escrita que os diários preservam são instáveis como os seus criadores, pois:

[...] o narrador não está fixo, ele se relaciona com outros textos, outras pessoas, outros tempos e esse relacionamento molda a imagem que ele quer de si e a imagem daquilo que ele vê e faz. A escrita sobre si mesmo é como um projeto: parte de um ponto escolhido e de for- 
ma consciente chega a outro ponto que o autor quis com determinados objetivos. É uma manipulação de um todo incoerente para criar um recorte coerente. (PIRES, 2010, p. 5)

A escrita autobiográfica requer uma certa sistemática, uma organização prévia por parte do autor. Ele e só ele é quem vai definir o que vai ser mostrado, o que vai ser suprimido e o faz tendo a memória como substrato. Assim, reconhecemos a escrita autobiográfica como "um trabalho de seleção e recorte da memória, que por sua vez, também, já é um recorte. Portanto, escrever de si é o recorte do recorte. Não podemos nunca tomar como verdade 0 que é dito, como um discurso pessoal sobre a verdade", pois não é (PIRES, 2010, p. 5).

Em seu estudo sobre a escrita autobiográfica de Nísia Floresta, Duarte (2009) estabelece três niveis narrativos. 0 primeiro está relacionado à viagem propriamente dita: "os deslocamentos, contratempos, passeios, festas populares, enfim, o conjunto de pormenores que preenchem cada instante presente da viagem" (2009, p. 82). Um segundo nível comporta a escrita de si, propriamente dita:

[...] a incursão que realiza em seu interior, seja em busca de lembranças de um passado familiar, seja nos instantes em que se isola do presente exterior próximo e se refugia em experiências de caráter íntimo. É quando o relato de viagem transforma-se em diário íntimo, e a autora registra os pensamentos de caráter pessoal, os devaneios, a confissão de saudades dos parentes e da pátria ou a alegria pela chegada de notícias. Trata-se, portanto, do espaço narrativo em que se encontram informações nitidamente autobiográficas, como as lembranças de aniversários e morte dos entes queridos. (DUARTE, 2009, p. 82)

Um terceiro e último nível engloba a imersão da autora pela "História e literaturas latinas, com suas reflexões e tomadas de posição acerca dos acontecimentos político-sociais" (DUARTE, 2009, p. 82). Estabelecendo parâme- tros de comparação com os níveis estabelecidos por Duarte (2009) para os relatos do "Diário de Bordo", consideramos que ainda que não exista uma divisão temática rígida, essa estrutura também se encontra presente na narrativa de Cecília Meireles. O que fica mais evidenciado são os dois primeiros níveis: o primeiro, também voltado à discussão dos acontecimentos da viagem, ao cotidiano do navio, às conversas e aos encontros com os passageiros, com a tripulação, às atividades desenvolvidas nas cidades onde o navio faz escala; um segundo nível, que é o mais consistente, onde a narradora se debruça sobre as suas reflexões, ao devaneio e suas experiências pessoais, sobretudo quando o navio deixa Recife, o último porto onde o navio faz escala e se lança à travessia do Atlântico. De um total de vinte e duas crônicas, a travessia será o mote de quatorze delas, em quatorze dias de mar aberto, onde os dias e as noites passam lentamente, onde os passageiros se encontram recolhidos às suas próprias cabines, onde raros são os momentos de encontro e as conversas com os demais passageiros. É nesse nível que ela se detém: é onde se debruça sobre o imponderável da viagem e da própria vida, e que coincide com o momento em que o navio faz a travessia do Atlântico em direção a Portugal.

Embora se manifeste com menor regularidade, o terceiro nível também está presente nas crônicas de Cecília Meireles. Ela se refere, de forma breve, à situação econômico-cultural das cidades visitadas, ao momento político -educacional que os Estados atravessam. Em algumas passagens, faz menções à sua vida profissional, porém, essas questões não estão enfatizadas a ponto de se tornarem pontos fulcrais na narrativa, pois são outros os objetivos e são outros os leitores a quem ela endereça a sua escrita de viagem. Ela não tem mais aqueles objetivos da coluna "Comentário", do Diário de Notícias, onde a tônica que prevale- 
cia era endereçada ao embate político, a projetar as concepções educacionais e contribuir para divulgar e difundir as inovações pensadas e introduzidas pelos reformadores ligados ao movimento da Escola Nova.

Da capital pernambucana em diante, como referido acima, a linguagem utilizada se torna cada vez mais intimista, mais melancólica e fica evidenciado o tom contemplativo das crônicas. Depois da euforia dos passageiros, enquanto o navio fazia escala, estes parecem mais recolhidos às suas próprias cabines e divagações. Os longos dias da travessia incentivam o recolhimento e instala-se um misto de introspecção e expectativa pelo desembarque que se aproxima. Cecília continua a relatar as atividades dos passageiros, da tripulação, os projetos empreendidos por Correia Dias e a cogitar sobre aqueles que irão desenvolver em Portugal.

As crônicas evidenciam o cotidiano da viagem que, àquela altura da travessia, se restringia aos longos e solitários dias na balaustrada do navio a observar os peixes, a coloração do oceano e dos céus. Poucas atividades envolvendo os passageiros são registradas: a festa em benefício dos músicos da orquestra do Cuyabá, o batismo daqueles que pela primeira vez fazem esta travessia (MEIRELES, 01/10/1934). Cecília confessa a sua escassa tendência esportiva, revela sentir uma certa aflição com os preparativos para a festa e mais uma vez, consola-se com os peixes voadores que ferem com o seu voo a vista mais distraída, (MEIRELES, 09/10/1934) avistados em sua luminosa trajetória aérea:

A passagem do Equador festejou-se com um pequeno baile no tombadilho. A noite esteve muito quente mas com um céu todo coberto de estrelas. Houve um batismo e uma crisma. A crisma foi do almirante Rogério Siqueira, que resolveu fazer-se agora 'globe-trotter', e, naturalmente para variar de personalidade, inventou essa mudança de nome. (MEIRELES, 01/10/1934)
Entre temores, receios, dúvidas, angústias, alegrias e surpresas e tantas outras situações únicas e/ou improváveis, que capturam e cativam o seu olhar, ela menciona as ilhas avistadas durante a viagem (Fernando de Noronha, Cabo Verde, Maio, Fuerteventura); o Carlyle, um navio de guerra que passa todo iluminado, destacando-se da noite negra como um barco de ouro, um barco enfeitado de estrelas e confirma a sua condição de poeta, qualidade indispensável para inventar novidades imaginárias que dão um deslumbramento transitório e imortal - duas qualidades indispensáveis à beleza. (MEIRELES, 09/10/1934)

Além dos tipos humanos exóticos e suas idiossincrasias, Cecília Meireles também tece reflexões sobre os invisíveis aos olhos dos turistas convencionais. Em Recife, são os trabalhadores que carregam de carvão o navio, e repara nos passageiros da terceira classe, muitos dos quais retornam ao seu país de origem sem a fama e a fortuna desejadas como tantos dos seus conterrâneos, os chamados "brasileiros de torna viagem"10

A escrita de si segue um rumo diverso dos navios que têm porto certo. Se ela é intencional, se segue alguns ritos, também se constrói de forma aleatória e há que se recordar, ainda, que a escrita autorreferencial só precisa ter sentido para aquele que escreve, ainda que sejam, como no caso do "Diário de Bordo", endereçadas ao público leitor de um jornal popular. Se por um acaso elas são tomadas como fontes para investigar essa ou aqueloutra questão, é importante que o pesquisador tenha a segu-

10 "Os brasileiros de torna-viagens, conhecidos em Portugal simplesmente como 'brasileiros', são parte fundamental da história da emigração portuguesa. Foram eles os imigrantes que retornaram à pátria após alguns tempo no Brasil e que, a partir do século XIX, passaram a fazer parte do universo simbólico português. [...] fixou-se a imagem do regressado rico e também muito estúpido, ganancioso, usurário e faminto por comentas e nobilitação. Era o novo-rico alardeador, de costumes exóticos, com sotaque e roupas diferentes". (MACHADO, 2005, p. 35) 
rança de atentar para certas considerações, como observado por Bourdieu (1996, p. 184):

Sem dúvida, cabe supor que o relato autobiográfico se baseia sempre, ou pelo menos em parte, na preocupação de dar sentido, de tornar razoável, de extrair uma lógica ao mesmo tempo retrospectiva e prospectiva, uma consistência e uma constância, estabelecendo relações inteligiveis, como a do efeito à causa eficiente ou final, entre os estados sucessivos, assim constituídos em etapas de um desenvolvimento necessário [...].

A narrativa não é toda a verdade nem contempla "toda a experiência daquele que viveu e escreveu" (PIRES, 2010, p. 5). Nas crônicas não estão evidenciados apenas os acontecimentos do navio, muito menos todas as experiências da narradora em sua viagem a Portugal. Elas trazem aquilo que é possivel, que cabe e se harmoniza ao espaço exíguo das colunas de um jornal. Vale lembrar, como sugere Borges (2009, p. 233), que:

Como nós, nossos personagens históricos não são modelos de coerência, de continuidade, de racionalidade; como para nós, as tensões entre o vivido e o que foi imaginado e desejado são fundamentais em suas vidas. $E$, para eles, como para nós, há uma parte indecifrável do aleatório, do imprevisível, do misterioso da vida (a não ser que acreditemos em alguma espécie de 'Divina Providência').

A narrativa de viagem de Cecília Meireles é feita da junção de todos os pormenores que pertencem ao seu universo, mas ela o faz com maestria, "sem descartar o que é comum aos

\section{Referências}

BORGES, Vavy Pacheco. O "eu" e o "outro" na relação biográfica: algumas reflexões. In: NAXARA, Márcia; MARSON, Izabel; BREPOHL, Marion (Orgs.). Figurações do outro. Uberlândia: EDUFU, 2009. p. 225-238.

BOURDIEU, Pierre. A ilusão biográfica. IN FERREIRA, Marieta de Moraes e AMADO, Janaina. Usos \& abu- poetas: pensar a travessia em perspectiva simbólica - ora subjetivando os contatos, ora tecendo reminiscências e sentimentos - a partir de uma escrita poética e profundamente criadora" (PIMENTA, 2015, p. 61). Por distintas vezes, a faceta profissional surge, entremostrada nos diálogos que tece com os educadores que encontra em Vitória, como Attilio Vivacqua, antigo secretário da Educação do Espírito Santo, e jornalistas como Altamiro Requião, com quem se põe a par da situação política do Estado da Bahia. Também surge do dia a dia do navio, das conversas agradáveis e desagradáveis do passadiço do Cuyabá, dos pequenos contratempos e das expectativas do que os espera em Portugal: as conferências, as entrevistas, a visita aos familiares, as cerimônias, as instituições e cidades que visitarão. Mas o que parece mover e comover a poeta que teceu tantos laços epistolares por sobre o Atlântico é a expectativa de reconhecer os amigos, ao desembarcar. A face íntima prevalece, ela domina a narrativa e aponta os sentidos, as expectativas e as impressões da viagem. Permite entender parte do universo de quem escreve, de quem questiona o seu lugar e também o panorama cultural, político e educacional brasileiro do período. Analisar as crônicas do "Diário de Bordo", que não é um documento escrito com esses objetivos, ainda assim fornece recursos suficientes para entender quem era, o que pretendia e como pensou o diálogo de uma jornalista, educadora e poeta, com as questões do seu tempo.

sos da história oral. 8a ed. Rio de Janeiro: Editora da Fundação Getúlio Vargas, 1996. p. 183-191.

DAMASCENO, Darci. Cronologia de publicação de Cecília Meireles em várias revistas: 1929-1940. Rio de Janeiro, [s.d.]. N. p. Original. Manuscrito. Inclui textos de crítica e ocorre referência à bibliografia 
de Cecília Meireles de 1940-1965. 26, 2, 36. Arquivo Darci Damasceno, Seção de Manuscritos da Biblioteca Nacional. Rio de Janeiro, Brasil.

DEL PRIORE, Mary. Biografia: quando o indivíduo encontra a história. Topoi, v. 10, n. 19, p. 7-16, jul./dez. 2009.

DUARTE, Constância Lima. As viagens e o discurso autobiográfico de Nísia Floresta. Matraga, Rio de Janeiro, v. 16, n. 25, p. 73-87, jul./dez. 2009.

FERREIRA, Marieta de Moraes. Diário pessoal, autobiografia e fontes orais: a trajetória de Pierre Deffontaines. In: INTERNATIONAL ORAL HISTORY CONFERENCE, 10., 1998, Rio de Janeiro. Oral history challenges for the 21st century: proceedings [of the] $X$ International Oral History Conference / Eds. Ilana Strozemberg... [et al]. Anais... Rio de Janeiro: CPDOC/FGV/Casa Oswaldo Cruz, 1998. v. 1. p. 379-386.

LACERDA, Lílian Maria de. Lendo vidas: a memória como escritura autobiográfica. In: MIGNOT, Ana Chrystina Venâncio; BASTOS, Maria Helena Câmara; CUNHA, Maria Teresa Santos. (Orgs). Refúgios do eu: educação, história e escrita autobiográfica. Florianópolis: Ed. Mulheres, 2000. p. 81-108.

LEITE, Miriam Lifchitz Moreira Leite. Livros de viagem (1803-1900). Rio de Janeiro: Editora da UFRJ, 1997.

MACHADO, Igor José de Renó. O “brasileiro de tornaviagens" e o lugar do Brasil em Portugal. Estudos Históricos, Rio de Janeiro, n. 35, p. 47-67, jan./jun. 2005.

MEIRELES, Cecília. Diário de Bordo. (Ilustrações de Fernando Correia Dias e Prefácio por Jussara Pimenta). 1ed. São Paulo: Editora Global, 2015.

MEIRELES, Cecília, 1901-1964. Diário de Bordo/Cecília Meireles; ilustrações Fernando Correia Dias; apresentação Alberto da Costa e Silva; prefácio e posfácio Jussara Pimenta. São Paulo: Global, 2014.

MEIRELES, Cecília. “Diário de Bordo”. A Nação, Rio de Janeiro, 02 de dezembro de 1934, p. 2. "Suplemento Literário". (Escrito em 02/10/1934 e publicado juntamente com o relato dos dias 03 e 04 de outubro de 1934).
MEIRELES, Cecília. “Diário de Bordo". A Nação, Rio de Janeiro, 11/11/1934, p. 2. "Suplemento Literário". (Escrito em 26/09/1934 e publicado juntamente com o relato do dia 27 de setembro de 1934).

MEIRELES, Cecília. "Diário de Bordo". A Nação, Rio de Janeiro, 1934, p. 2. "Suplemento Literário". (Escrito em 28/09/1934 e publicado juntamente com o relato do dia 29 de setembro de 1934).

MEIRELES, Cecília. “Diário de Bordo”. A Nação, Rio de Janeiro, 1934, p. 2. "Suplemento Literário". (Escrito em 30/09/1934 e publicado juntamente com o relato do dia 01 de outubro de 1934).

MEIRELES, Cecília. "Diário de Bordo". A Nação, Rio de Janeiro, 1934. (sem data). p. 2. "Suplemento Literário".

MEIRELES, Cecília. "Diário de Bordo". A Nação, Rio de Janeiro, 1934, p. 2. "Suplemento Literário". (Escrito em 06/10/1934 e publicado juntamente com o relato do dia 05 de outubro de 1934).

MEIRELES, Cecília. “Diário de Bordo". A Nação, Rio de Janeiro, 23 de dezembro de 1934, p. 2. "Suplemento Literário". (Escrito em 10/10/1934 e publicado juntamente com o relato do dia 11 de outubro de 1934).

MEIRELES, Cecília. Ainda os museus. In: MEIRELES, Cecília. Crônicas de Viagem. Rio de Janeiro: Nova Fronteira, 1998. v.1, p. 291-293.

MEIRELES, Cecília. Criança, meu amor. Rio de Janeiro: Tipografia do Anuário do Brasil, 1924.

MEIRELES, Cecília. Roma, turistas e viajantes. In: MEIRELES, Cecília. Crônicas de Viagem. Rio de Janeiro: Nova Fronteira, 1999. p. 101-104.

MICELI, Paulo. 0 ponto onde estamos: viagens e viajantes na história da expansão e da conquista. São Paulo: Página Aberta, 1994.

MIGNOT, Ana Chrystina Venancio; SILVA, Alexandra Lima da. Tão longe, tão perto: escrita de si em relatórios de viagens. Educação em Revista, Belo Horizonte, v. 27, n. 1, p. 435-458, abr. 2011.

MIGNOT, Ana Chrystina Venâncio. Editando o legado pioneiro: o arquivo de uma educadora. In: MIGNOT, Ana Chrystina Venâncio; BASTOS, Maria Helena Câ- 
mara; CUNHA, Maria Teresa Santos. (Orgs.). Refúgios do eu: educação, história e escrita autobiográfica. Florianópolis: Ed. Mulheres, 2000. p. 123-144.

MIGNOT, Ana Chrystina Venâncio; BASTOS, Maria Helena Câmara; CUNHA, Maria Teresa Santos. (Orgs).

Refúgios do eu: educação, história e escrita autobiográfica. Florianópolis: Ed. Mulheres, 2000.

MUZART, Zahidé Lupinacci. Do navegar e de navegantes. In: MIGNOT, Ana Chrystina Venâncio; BASTOS, Maria Helena Câmara; CUNHA, Maria Teresa Santos. (Orgs.). Refúgios do eu: educação, história e escrita autobiográfica. Florianópolis: Ed. Mulheres, 2000. p. 181-189.

NORA, Pierre. Entre memória e história. A problemática dos lugares. Proj. História, São Paulo, v. 10, p. 7-28, dez. 1993.

PIMENTA, J. S. As narrativas de viagem de uma educadora publicadas no jornal A Nação (1934). Rev. EDUCA, Porto Velho (RO), v.2, n.4, p. 56-70, 2015.

PIMENTA, J. S. Leitura, arte e educação: a biblioteca infantil do Pavilhão Mourisco. Curitiba: Editora CRV, 2011.

PIMENTA, J. S. As duas margens do Atlântico: um projeto de integração entre dois povos na viagem de Cecília Meireles a Portugal (1934). 2008. 374 f. Tese (Doutorado em Educação) - Faculdade de Educação, Universidade do Estado do Rio de Janeiro, Rio de Janeiro, 2008.

PIMENTA, J. S. Rastro de deslumbramento: Cecília Meireles em Portugal. In: MIGNOT, A. C.; GONDRA, J. G. (Orgs.). Viagens Pedagógicas. São Paulo: Cortez, 2007. p. 163-194.

PIMENTEL, Thaís Velloso Cougo. De viagens e de narrativas: viajantes brasileiros no além-mar (1913-
1957). 1998. 200 f. Tese (Doutorado em História Social) - Faculdade de Filosofia, Ciências e Letras, Universidade de São Paulo, São Paulo, 1998.

PIRES, João Ricardo Ferreira. A narrativa de viagem como exercício autorreferencial da memória: o exemplo de D. Pedro II. In: XIV encontro regional da ANPUH-Rio: Memória e Patrimônio, 14., 2010, Rio de Janeiro. Anais... Rio de Janeiro: ANPUH, 2010. p. 1-11.

SOUZA, Anlene Gomes de. 0 estrangeiro e a cidade: o Rio de Janeiro e o imaginário da viagem na primeira metade do século XX. 1995. 172 f. Dissertação (Mestrado em História) - Departamento de História, Pontificia Universidade Católica do Rio de Janeiro, Rio de Janeiro, 1995.

SANTOS, Claudete Daflon dos. A viagem e a escrita: uma reflexão sobre a importância da viagem na formação e produção intelectual de escritoresviajantes brasileiros. 2002. 225 f. Tese (Doutorado) - Departamento de Letras. Pontifícia Universidade Católica do Rio de Janeiro.

VIÑAO, Antonio. Las autobiografias, memorias y diarios como fuente histórico-educativa: tipología y usos. Teias, Revista da Faculdade de Educação da UERJ, v. 1, n. 1, p. 1-26, 2000 a.

VIÑAO, Antonio. A modo de prólogo, refúgio del yo, refúgios de otros. In: MIGNOT, Ana Chrystina Venâncio; BASTOS, Maria Helena Câmara; CUNHA, Maria Teresa Santos. (Orgs.). Refúgios do eu: educação, história e escrita autobiográfica. Florianópolis: Mulheres, 2000b. p. 7-11.

Recebido em: 15.03.2017

Aprovado em: 28.06.2017

Jussara Santos Pimenta é Doutora em Educação. Professora do Departamento de Ciências da Educação, da Universidade Federal de Rondônia (UNIR) Campus Porto Velho - RO. Professora permanente do PPGEE/MEPE/UNIR. Líder do MNEMOS - Grupo de Estudos Interdisciplinares em Educação, História e Memória, Linha de Pesquisa: Memórias e Histórias das Instituições Escolares. e-mail: jussara.pimenta@unir.br 